\title{
Anal incontinence, urinary incontinence and sexual problems in primiparous women - a comparison between women with episiotomy only and women with episiotomy and obstetric anal sphincter injury
}

Mona Stedenfeldt ${ }^{1,2^{*}}$, Jouko Pirhonen ${ }^{1}$, Ellen Blix ${ }^{3}$, Tom Wilsgaard ${ }^{4}$, Barthold Vonen² and Pål Øian ${ }^{2,5}$

\begin{abstract}
Background: Obstetric anal sphincter injuries (OASIS) might cause anal incontinence (Al) and sexual dysfunction, and might be associated with urinary incontinence (UI). Episiotomy has been identified both as a risk and a protective factor of OASIS. Lately, episiotomies with specific characteristics have shown to be protective against the risk of OASIS. However, little is known about episiotomy characteristics and pelvic floor dysfunction. This study investigates Al, $\mathrm{UI}$, and sexual problems in primiparous women with episiotomy, comparing women with and without OASIS. Associations between episiotomy characteristics and Al, UI, and sexual problems were assessed.

Methods: This is a matched case-control study investigating 74 women with one vaginal birth, all with an episiotomy. Among these, 37 women sustained OASIS and were compared to 37 women without OASIS. The two groups were matched for vacuum/forceps. Al, UI and sexual problem symptoms were obtained from St. Mark's scoring-tool and self-administered questionnaires. The episiotomy characteristics were investigated and results assessed for the whole group.
\end{abstract}

Results: The mean time from birth was 34.5 months (range1.3-78.2) for those with OASIS and 25.9 months (range 7.0-57.4) for those without OASIS, respectively. More women with OASIS reported Al: 14 (38\%) vs. 3 (8\%) $p=0.05$ (OR 4.66, 95\% Cl 1.34-16.33) as well as more problem with sexual desire $p=0.02$ (OR 7.62, 95\% Cl 1.30-44.64) compared to women without OASIS. We found no association between episiotomy with protective characteristics and dysfunctions.

Conclusion: Women with OASIS had more AI and sexual problems than those without OASIS. Episiotomy characteristics varied greatly between the women. Episiotomy with protective characteristics was not associated with increased dysfunctions. OASIS should be avoided, and correct episiotomy used if indicated.

Keywords: Obstetric anal sphincter injuries, Episiotomy characteristics, Anal incontinence, Urinary incontinence, Sexual problems

\footnotetext{
* Correspondence: mona.stedenfeldt@unn.no

'The National Advisory Unit on Continence and Pelvic Floor Health, University Hospital of North Norway, Tromsø, Norway

${ }^{2}$ Department of Clinical Medicine, Women's Health and Perinatology Research

Group, Faculty of Health Science, University of Tromsø, Tromsø, Norway

Full list of author information is available at the end of the article
} 


\section{Background}

Obstetric anal sphincter injury is a serious complication of vaginal delivery that can cause significant morbidity, leading to anal incontinence (AI) in $30-50 \%$ of the women despite adequate repair [1-4]. These injuries can cause sexual dysfunctions [2], and might be associated with urinary incontinence (UI) [5]. Postpartum AI, UI, and sexual dysfunctions are all distressing health problems and have potentially detrimental effects on the quality of life [6-8].

Episiotomy is one of the most frequently used obstetric procedure as well as one of the most debated. There are great variations in both techniques and indications amongst midwives and obstetricians $[9,10]$ and there are conflicting results regarding the association between episiotomy and OASIS [11-13]. The most common episiotomy techniques described in the literature are midline and mediolateral technique. Midline episiotomy starts at the posterior fourchette followed by a straight downward cut, the mediolateral episiotomy starts at the posterior fourchette and continues with a cut $40-60^{\circ}$ from the midline [14]. Lateral episiotomy is rarely described even though studies show that lateral episiotomy is a tradition in some European countries [15-17], and commonly performed unintentionally $[9,11,16]$. Lateral episiotomy starts to the left or right of the midline, at either $4-5$ or $7-8$ o'clock and the cut is angled $40-60^{\circ}$ from the midline [14].

Research has found that clinicians very often perform mediolateral episiotomy improperly $[12,16,18,19]$. This is important because a correct mediolateral episiotomy with an angle of $40-60^{\circ}$ is shown to have protective properties and decrease the risk of sustaining OASIS compared to episiotomies with narrower angles [12,18]. In a recent case-control study, we sought to assess associations between episiotomy characteristics and OASIS and found that a lateral episiotomy with correct angle, sufficient length and depth reduced the risk of sustaining OASIS compared to mediolateral episiotomy [18].

Episiotomy is suggested to be associated with postpartum dyspareunia and perineal pain [20,21]. Further, mediolateral episiotomy is thought to cause more perineal pain and dyspareunia compared to midline episiotomy [22]. On the other hand, a recent study found no difference in perineal pain between women with midline, mediolateral and lateral episiotomy when the episiotomy technique used was investigated $0-3$ days after delivery [16].

The primary aim of this study was to assess if there were differences in prevalence of AI, UI and sexual problems in women with episiotomy and OASIS compared to women with episiotomy only. Secondly, to assess if episiotomy characteristics were associated with AI, UI and sexual problems.

\section{Methods}

This study was the second part of a matched case-control study carried out at the University Hospital of North Norway and Nordland Hospital (permission for both hospitals: Regional Ethics Committee of North Norway $(163 / 2008)$ [18]. Included in the study were primiparous women with OASIS who had episiotomy and clinically identified tears graded as 3a, 3b, 3c, or 4 [23], and women without OASIS who had episiotomy only. Procedures for diagnosing OASIS are similar at both units; if the midwife or physician responsible for the delivery suspect a sphincter tear, a specialist in obstetrics and gynecology confirms it, and the repair is done by an experienced obstetrician or colorectal surgeon [18].

The women were identified through the hospitals electronic patient journal system Partus ${ }^{\circ}$ (CSAM Health AS, Lysaker, Norway). Women were matched for ventouse/ forceps because of the strong association between OASIS and instrumental delivery. Fifty-three women with OASIS and 75 matched control women were eligible. The women were contacted and asked to participate by letter and phone-call. Five women were excluded because of language or pregnancy and 16 OASIS cases and 33 matched controls, a total of 49 women, declined to participate. Seventy-four eligible women $(70 \%$ of eligible cases and $50 \%$ of eligible controls) were willing to participate in the study [18].

After the women had signed an informed consent form, they were called in for a physical examination [18]. During the consultation, the introitus vagina/perineum was investigated for the episiotomy scar. One of the authors (MS) did the investigation and photography at mean 34.5 and 25.9 months after birth for women with and without OASIS, respectively. The photography was standardized with the women in stirrups and the camera in fixed positions [18]. Based on the photos taken, the episiotomy length, incision point, depth, distance from the anal canal, and angle given between the fixed points of the posterior fourchette, the episiotomy, and the most anterior point of the anal epithelium were measured (Figure 1) [18].

To differentiate the episiotomies based on the incision point they were categorized into hours as in an analog clock display: 6, 6-5, 5, 5-4, 4, 4-3, 3. Incision points equal to 6 and between $6-5$ were categorized as medial incision point, and incision point above 5 was categorized as lateral incision point. Further, the episiotomies were categorized into angles ranging as: $<15,16-30,31-45,46-60,>60^{\circ}$.

Bowel, urinary, and sexual problems were registered by questionnaires and scoring systems. AI was defined as an involuntary loss of flatus, liquid, or solid. Symptoms were registered with the St. Mark's scoring system, which is a validated interview tool consisting of seven questions for grading the severity of AI during the final four weeks [24]. The scores range from 0 to 24. In this study, the 


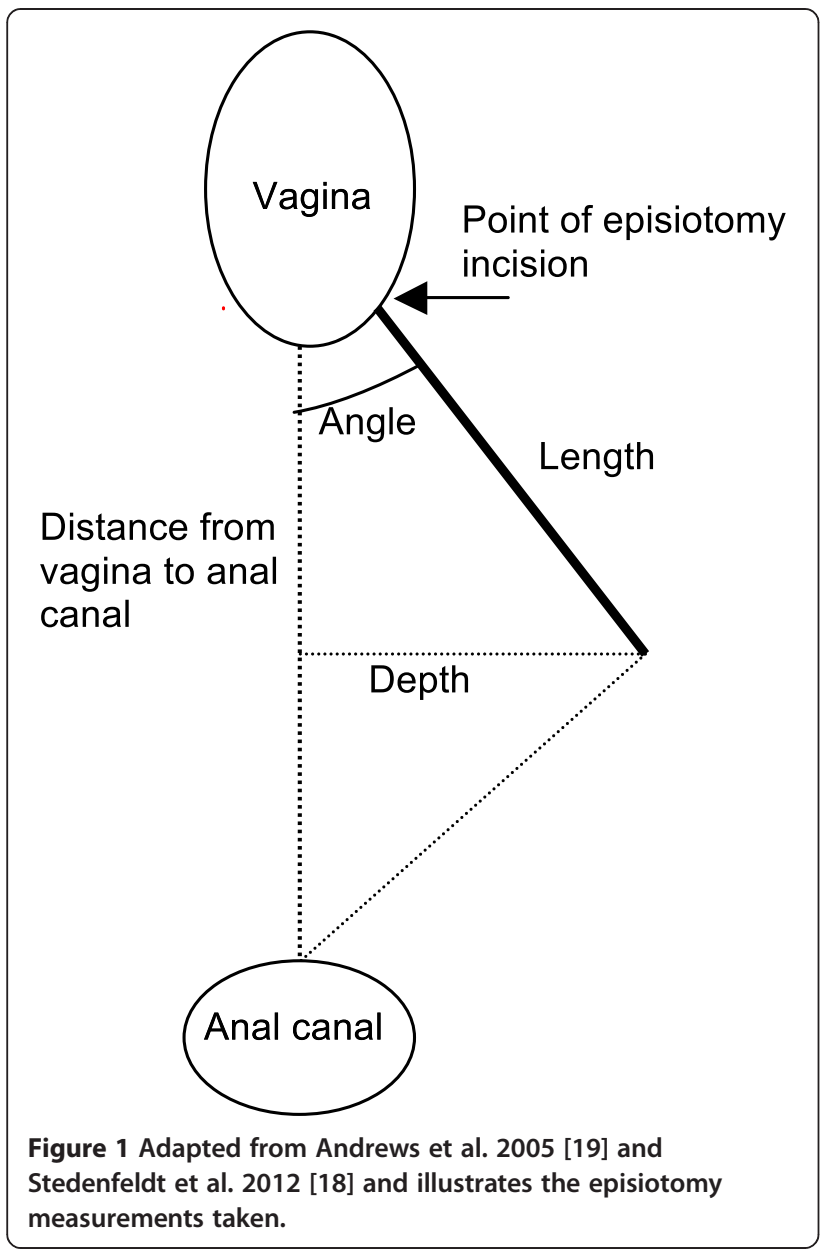

severity of symptoms was graded according to clinical relevance: $0-3=$ "no AI"; 4-8 = "mild/moderate"; $\geq 9=$ "severe". The scores were also dichotomized so that $0-3=$ "no AI" and $\geq 4=$ "AI". MS carried out all the interviews and scorings. UI was defined as a symptomatic involuntary loss of urine and documented by the validated selfadministered questionnaire ICIQ-UI SF, which was developed for assessing the type of UI as well as its prevalence, severity, and impact on quality of life $[25,26]$. The answers resulted in a sum ranging from 0 to 21 . Scores were also dichotomized so that $0=$ "no UI" and $\geq 1=$ "UI" [25]. Furthermore, according to clinical relevance, UI was categorized as 1-8 = "mild" and $\geq 9=$ "moderate/severe".

Sexual problems were evaluated by questions originally used by the Norwegian Institute of Public Health to assess sexual problems in Norway [27]. The women were asked whether they were sexually active, with the response options being "YES" or "NO". If the answer was "YES", the degree of sexual problems was measured by the question: "Have you experienced any of the sexual problems listed below during the past 12 months/or since sexual activity was retained after birth". The following three problems were listed: 1) reduced sexual desire, 2) orgasm problem, 3) experience of genital pain during intercourse. Response categories for each of the items were $0=$ "not active due to problems", $1=$ "problem all the time", $2=$ "problem nearly all the time", $3=$ "problem quite often", 4 = "problem quite rarely", and $5=$ "never problem".

Data were analyzed using SPSS version 18 (SPSS Inc, IL, USA). Conditional logistic regression models were used to assess differences between women with and without OASIS in the rate of AI, UI, and sexual problems. Spearman's correlation coefficient was used to estimate correlation between episiotomy characteristics and AI, UI and sexual problems for the groups combined. In a subgroup analysis of the women without OASIS, a two-sample $\mathrm{t}$-test was used to compare mean differences in St. Mark's score between $3 \mathrm{a}$ and $3 \mathrm{~b}$ versus $3 \mathrm{c}$ and 4 injuries. A two-sided 5\% significance level was used. The study was approved by the Regional Ethics Committee of North Norway (163/2008).

\section{Results}

Demographic data are presented in Table 1. Table 2 shows that anal incontinence was significantly more frequent in women with OASIS compared to women without OASIS, $14(38 \%)$ vs. three (8\%), $\mathrm{p}=0.05$ (OR 4.66, 95\% CI 1.34-16.33). In women with OASIS, eight (22\%) reported mild AI and six (16\%) moderate/severe AI (Table 2). In the group with no OASIS, there were two (5\%) women reporting mild AI and one (3\%) moderate/ severe AI. We observed a significant difference in AI symptoms between women with grade $3 \mathrm{c}$ and $4 \mathrm{com}$ pared to those with grade $3 \mathrm{a}$ and $3 \mathrm{~b}$ tears. The mean St. Mark's score was 3.9 higher for women with $3 \mathrm{c}$ and 4 injury compared to those with $3 \mathrm{a}$ and $\mathrm{b}$ injury $(95 \% \mathrm{CI}$ for

Table 1 Demographic characteristics in women with and without OASIS

\begin{tabular}{llll}
\hline & $\begin{array}{l}\text { Women with } \\
\text { OASIS (n= 37) }\end{array}$ & $\begin{array}{l}\text { Women without } \\
\text { OASIS (n= 37) }\end{array}$ & p value*** \\
\hline $\begin{array}{l}\text { Mother's age (years) } \\
\text { at delivery* }\end{array}$ & $30(6.3)$ & $29(6.4)$ & 0.46 \\
Range & $19-41$ & $17-41$ & \\
$\begin{array}{l}\text { Birthweight (g)* } \\
\text { Range }\end{array}$ & $3764(662)$ & $3376(472)$ & 0.01 \\
$\begin{array}{l}\text { Head circumference } \\
\text { (cm) }\end{array}$ & $36(1.6)$ & $35(1.8)$ & 0.04 \\
$\begin{array}{l}\text { Range } \\
\text { Time from birth to }\end{array}$ & $32-4245(21.6)$ & $25.9(13.8)$ & 0.06 \\
assessment (months) & & $1922-4180$ & \\
Range & $1.3-78.2$ & $7.0-57.4$ & \\
Instrumental delivery* & $19(51)$ & $19(51)$ & N/A \\
\hline
\end{tabular}

*The values are mean (standard deviation) and range or $n(\%)$

**p values from univariate conditional logistic regression. 
Table 2 Anal incontinence, urinary incontinence and sexual problems and OR for OASIS in women with episiotomy

\begin{tabular}{|c|c|c|c|c|c|}
\hline & OASIS, yes $(n=37)^{*}$ & OASIS, no $(n=37)^{*}$ & p-value ${ }^{* *}$ & $\mathrm{OR}^{* *}$ & $(95 \% \mathrm{Cl})^{* *}$ \\
\hline \multicolumn{6}{|l|}{ Anal Incontinence } \\
\hline St. Mark's score < 4 & $23(62)$ & $34(92)$ & & 1.00 & Reference \\
\hline St. Mark's score $\geq 4$ & $14(38)$ & $3(8)$ & 0.02 & 4.66 & $(1.34-16.33)$ \\
\hline No Al, St. Mark's score < 4 & $23(62)$ & $34(92)$ & & 1.00 & Reference \\
\hline St. Mark's score 4 - 8 & $8(22)$ & $2(5)$ & 0.08 & 4.00 & $(0.85-18.80)$ \\
\hline St. Mark's score $\geq 9$ & $6(16)$ & $1(3)$ & 0.09 & 6.00 & $(0.72-49.80)$ \\
\hline \multicolumn{6}{|l|}{ Urinary Incontinence } \\
\hline No UI, ICIQ-UI SF ${ }^{\#}=0$ & $20(54)$ & $22(60)$ & & 1.00 & Reference \\
\hline UI, ICIQ-UI SF ${ }^{\#} \geq 1$ & $17(46)$ & $15(40)$ & 0.60 & 1.30 & $(0.46-3.84)$ \\
\hline No UI, ICIQ-UI SF $=0$ & $20(54)$ & $22(60)$ & & 1.00 & Reference \\
\hline Mild UI, ICIQ-UI SF 1 - 8 & $13(35)$ & $12(32)$ & 0.74 & 1.30 & $(0.35-4.67)$ \\
\hline Moderate/severe UI, ICIQ-UI SF ${ }^{\#} \geq 9$ & $4(11)$ & $3(8)$ & 0.70 & 1.30 & $(0.30-5.96)$ \\
\hline \multicolumn{6}{|c|}{ Combined anal and urinary incontinence } \\
\hline No & $27(73)$ & $34(92)$ & & 1.00 & Reference \\
\hline Yes & $10(27)$ & $3(8)$ & 0.07 & 3.30 & $(0.92-12.1)$ \\
\hline \multicolumn{6}{|l|}{ Sexual problem desire } \\
\hline Score 5 (no problem) & $4(12)$ & $16(43)$ & & & Reference \\
\hline Score 4 & $16(48)$ & $12(32)$ & 0.04 & 6.94 & $(1.05-45.91)$ \\
\hline Score 3 & $6(18)$ & $5(14)$ & 0.12 & 3.84 & $(6.99-21.11)$ \\
\hline Score 1-2 & $7(21)$ & $4(11)$ & 0.02 & 7.62 & $(1.30-44.64)$ \\
\hline \multicolumn{6}{|l|}{ Sexual problem orgasm } \\
\hline Score 5 (no problem) & $10(30)$ & $19(51)$ & & & Reference \\
\hline Score 4 & $18(54)$ & $11(29)$ & 0.36 & 2.49 & $(0.35-17.66)$ \\
\hline Score 3 & $2(6)$ & $5(13)$ & 0.90 & 0.89 & $(0.14-5.90)$ \\
\hline Score 1-2 & $3(9)$ & $2(5)$ & 0.07 & 3.32 & $(0.88-12.49)$ \\
\hline \multicolumn{6}{|l|}{ Sexual problem with pain } \\
\hline Score 5 (no problem) & $16(49)$ & $22(59)$ & & & Reference \\
\hline Score 4 & $9(27)$ & $7(19)$ & 0.13 & 4.37 & $(0.63-30.16)$ \\
\hline Score 3 & $1(3)$ & $6(16)$ & 0.29 & 0.30 & $(0.03-2.83)$ \\
\hline Score 1-2 & $7(21)$ & $2(5)$ & 0.21 & 2.44 & $(0.61-9.75)$ \\
\hline
\end{tabular}

$\mathrm{OASIS}$, Obstetric anal sphincter injury; $\mathrm{Al}$, anal incontinence; $\mathrm{Ul}$, urinary incontinence; $\mathrm{OR}$, odds ratio; $\mathrm{Cl}$, confidence interval.

*The values are $\mathrm{n}(\%)$.

**Univariate conditional logistic regression models. ORs are presented as per unit increase in score point or contrasted to a reference level.

"International Consultation on Incontinence Modular Questionnaire Urinary Incontinence Short Form.

mean difference, $0.85-7.01, \mathrm{p}=0.01)$. Although not significant $10(27 \%)$ women with OASIS vs. $3(8 \%)$ women without OASIS $\mathrm{p}=0.07$ (OR 3.30, 95\% CI 0.92-12.1) reported both $\mathrm{AI}$ and $\mathrm{UI}$ incontinence.

There were no significant difference in the rate of UI between women with OASIS and women without OASIS $\mathrm{p}=0.60$ (OR 1.30 95\% CI 0.30-5.96). Seventeen (46\%) women with, and 15 (40\%) without OASIS experienced involuntary urine leakage once a week or less (Table 2).

Women with OASIS reported significantly more problem with sexual desire compared with women without OASIS, $\mathrm{p}=0.02$ (OR 7.62, 95\% CI 1.30- 44.64) (Table 2).
Only two (5.4\%) women with OASIS reported no sexual problems compared to $12(32.4 \%)$ in women without. On the other hand, five $(13.5 \%)$ women with OASIS compared to no $(0 \%)$ women without OASIS reported no sexual activity or sexual problems all the time (Figure 2).

The episiotomy characteristics varied greatly across the cohort. While we investigated dysfunctions by comparing women with OASIS with women without OASIS, we chose to assess the association between episiotomy characteristics with dysfunctions in all 74 women together. Episiotomy length $\mathrm{E}$ ranged from $0.5 \mathrm{~cm}$ to $3.2 \mathrm{~cm}($ mean $=1.5, \mathrm{SD}=0.7)$ and episiotomy depth $\mathrm{B}$ 


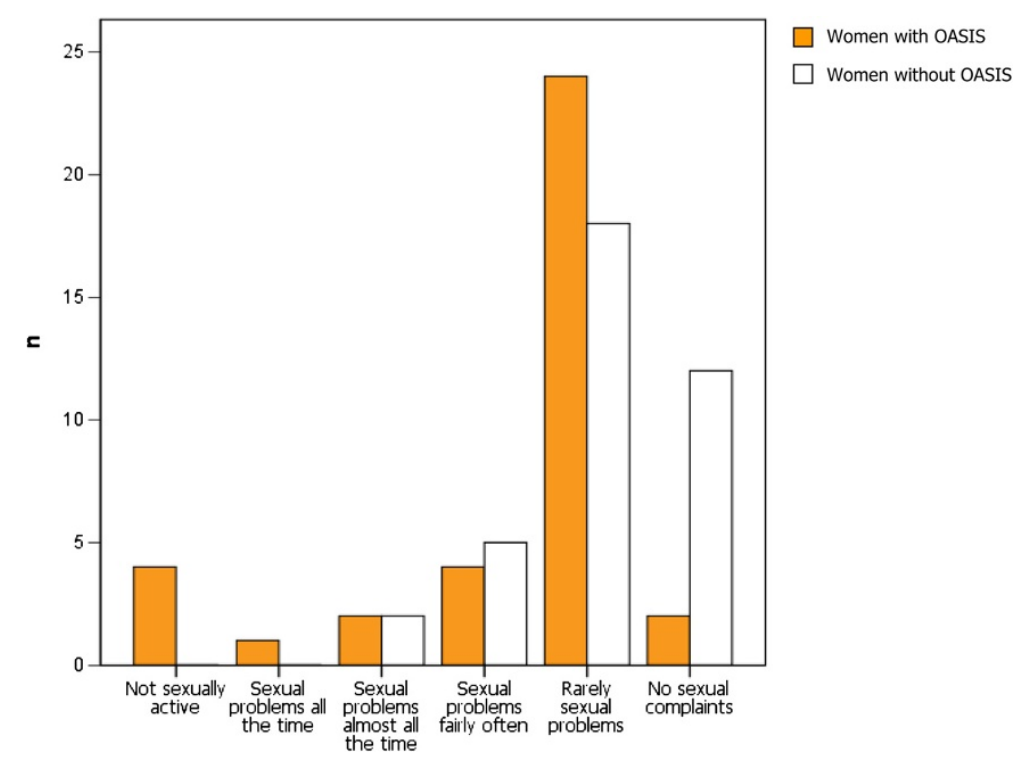

Figure 2 Combined sexual problems: desire, orgasm and pain (scores) for women with and without OASIS.

ranged from $0.0 \mathrm{~cm}$ to $3.0 \mathrm{~cm}$ (mean $=1.4, \mathrm{SD}=0.6)$. Table 3 shows episiotomies categorized according to incision point and width of angle. Sixty-five percent had a medial incision point (hour $=6$, and $6-5$ ) and 35\% were classified as lateral incision point (hour $\geq 5$ ).

Table 4 shows Spearman's correlation coefficients ( $r$ ) between dysfunction score and episiotomy characteristics. Two out of 12 coefficients were significant: a moderate degree of correlation was observed for total sexual problem score with episiotomy length and depth $(\mathrm{r}=$ 0.28 and 0.31 , respectively).

Table 3 Episiotomy characteristics based on incision point and angle range in $\mathbf{7 4}$ primiparous women

\begin{tabular}{lll}
\hline & Frequency & Percent \\
\hline Incision point* & 10 & 14 \\
Hour 6 & 38 & 51 \\
Hour 6-5 & 15 & 21 \\
Hour 5 & 9 & 12 \\
Hour 5-4 & 1 & 1 \\
Hour 4 & 1 & 1 \\
Hour 3 & & 10 \\
Angle range & 7 & 30 \\
$0-15$ & 22 & 24 \\
$16-30$ & 18 & 20 \\
$31-45$ & 15 & 16 \\
$46-60$ & 12 & \\
$61+$ & &
\end{tabular}

*according to an analog clock display.

\section{Discussion}

Women with OASIS reported significantly more AI and problem with sexual desire compared to women without OASIS. Episiotomy characteristics varied extensively between the women. We found no association between episiotomy characteristics and AI, UI. Episiotomy length (E) and depth (B) were associated with sexual problems. The correlation is positive, meaning that the episiotomies with protective characteristics of length and depth were associated with fewer problems.

\section{Obstetric anal sphincter injuries in relation to $\mathrm{Al}$ and sexual problems}

OASIS have consistently been associated with increased rate of AI and sexual problems. The mean rate of AI has been reported to be $39 \%$ (range 15-61\%) after primary repair $[1,4,28]$ although a recent report suggest that AI following OASIS can be minimized with appropriate

Table 4 Correlation between dysfunction score and episiotomy characteristics in $\mathbf{7 4}$ primiparous women*

\begin{tabular}{lllll}
\hline Dysfunctions & \multicolumn{3}{l}{ Episiotomy characteristics } \\
\cline { 2 - 5 } & $\begin{array}{l}\text { Episiotomy } \\
\text { length - E }\end{array}$ & $\begin{array}{l}\text { Episiotomy } \\
\text { depth - B }\end{array}$ & $\begin{array}{l}\text { Episiotomy } \\
\text { insertion } \\
\text { point - D }\end{array}$ & $\begin{array}{l}\text { Episiotomy } \\
\text { angle }\end{array}$ \\
\hline $\begin{array}{l}\text { Al (St.Mark's- } \\
\text { score) }\end{array}$ & -0.14 & -0.03 & -0.07 & 0.05 \\
UI (ICIQ UI SF) & -0.04 & 0.06 & 0.03 & 0.01 \\
$\begin{array}{l}\text { Sexual problem } \\
\text { (total score) }\end{array}$ & $0.28^{* *}$ & $0.31^{* *}$ & 0.08 & 0.04 \\
\hline
\end{tabular}

*Spearman's Rho coefficient is used to assess correlations. ${ }^{* *} \mathrm{p}<0.05$. 
repair by trained doctors [28]. Sexual problems after vaginal delivery in women sustaining OASIS have been reported to be $29-39 \%[29,30]$ compared to13-19\% for women with no OASIS $[29,30]$. We found that problems with desire were significantly more prevalent for women with OASIS, whereas problems with orgasm and pain were not significantly different between the groups.

The association we found between degree of injury and severity of AI symptoms further highlights that the degree of perineal damage is one of the key factors of postpartum pelvic floor dysfunction and is supported by earlier studies. Roos et al. [3] reported significantly poorer outcomes for women sustaining OASIS grades $3 \mathrm{c}$ and 4 than grades $3 \mathrm{a}$ and $3 \mathrm{~b}$, and de Leeuw et al. [1] found that the odds of developing AI significantly increased according to increased severity of injury.

\section{Episiotomy characteristics in relation to $\mathrm{Al}$ and sexual problems}

We found that all the episiotomy characteristics varied across the cohort. This corroborates with previous studies $[9,11,12]$. We have previously reported that specific characteristics were associated with decreased risk of sustaining OASIS [18]. This study found that there were no association between the episiotomy characteristic that decreased the risk of OASIS and increased dysfunctions such as AI, UI and sexual problems.

To the best of our knowledge only a few studies have looked at the actual episiotomy technique used in relation to pelvic floor dysfunctions. Episiotomy technique during delivery was assured to have an angle of $60^{\circ}$ in 60 primiparous women in a prospective study [31]. There was no OASIS in this group. After six months 51 women registered their symptoms of anal incontinence and perineal pain. Two women (4\%) registered symptoms of AI, whereas episiotomy related perineal pain was reported by seven (14\%) women. Fodstad et al. [16] assessed the episiotomy $0-3$ days after birth in 300 women and investigated perineal pain and blood loss. The episiotomies were classified as midline, mediolateral, and lateral and no difference in perineal pain and blood loss in relation to technique were found.

\section{High rates of $\mathrm{UI}$ in both groups}

This study reports high rates of UI in both groups and no significant difference which corroborated with previous results of Borello-France et al. [7] and de Leeuw et al. [1], indicating that the development of UI after delivery is caused by different anatomical injuries than OASIS.

\section{Study limitations}

The current study has limitations. It is a small retrospective study, and the results must therefore be interpreted with caution. Independent predictors such as pre-pregnancy AI, UI, and sexual complaints are unknown [32]. Follow-up time is another limitation since all described functions vary with time. Even though the mean follow-up time was not significantly different between the groups, the range was larger in women with OASIS compared to women without. Our study did not have a control group with an intact perineum, simply because it was too difficult to match the criteria of $51 \%$ instrumental delivery without episiotomy. Finally, birthweight was significantly higher in the case group compared to the control group and might be a potential confounder. Although birthweight has been reported to be a risk factor for OASIS [33], birthweight is not independently associated with AI [34,35]. As far as we know, birthweight has not been independently associated with either sexual problems or UI.

\section{Conclusion}

OASIS is the primary risk factor for AI and sexual problems in primiparous women with episiotomy. We did not find any association between episiotomy with protective characteristics and postpartum AI, UI and increased sexual problems. A correctly performed episiotomy may prevent OASIS. This study highlights that the sequelae after episiotomy with preventive characteristics is not as bad as having a sphincter injury.

\section{Abbreviations \\ OASIS: Obstetric anal sphincter injuries; UI: Urinary incontinence; Al: Anal incontinence; OR: Odds ratio.}

\section{Competing interests}

There are no competing interests. MS received a grant from the Northern Norway Regional Health Authority.

\section{Authors' contributions}

MS: project development, data collection, management and analyses, manuscript writing/editing; JP: project development, data management, manuscript writing/editing; EB: data analyses, manuscript writing/editing; TW: data analyses, manuscript writing/edition; BV: project development, manuscript writing/editing; $P \varnothing$ : project development, data management, manuscript writing/editing. All authors read and approved the final manuscript.

\section{Acknowledgment}

We thank professor Bente Træen for providing the original sexual problem questionnaire.

\section{Author details \\ ${ }^{1}$ The National Advisory Unit on Continence and Pelvic Floor Health, University Hospital of North Norway, Tromsø, Norway. ${ }^{2}$ Department of Clinical Medicine, Women's Health and Perinatology Research Group, Faculty of Health Science, University of Tromsø, Tromsø, Norway. ${ }^{3}$ Research Group Maternal, Reproductive and Children's Health, Faculty of Health, Oslo and Akershus University College of Applied Sciences, Oslo, Norway. ${ }^{4}$ Department of Community Medicine, Faculty of Health Science, University of Troms $\varnothing$, Troms $\varnothing$, Norway. ${ }^{5}$ Department of Obstetrics and Gynecology, University Hospital of North Norway, Tromsø, Nomay.}

Received: 6 May 2014 Accepted: 9 December 2014

Published online: 16 December 2014 


\section{References}

1. de Leeuw JW, Vierhout ME, Struijk PC, Hop WC, Wallenburg HC: Anal sphincter damage after vaginal delivery: functional outcome and risk factors for fecal incontinence. Acta Obstet Gynecol Scand 2001, 80:830-834.

2. Marsh F, Lynne R, Christine L, Alison W: Obstetric anal sphincter injury in the UK and its effect on bowel, bladder and sexual function. Eur J Obstet Gynecol Reprod Biol 2011, 154:223-227.

3. Roos AM, Thakar R, Sultan AH: Outcome of primary repair of obstetric anal sphincter injuries (OASIS): does the grade of tear matter? Ultrasound Obstet Gynecol 2010, 6:368-374

4. Norderval S, Nsubuga D, Bjelke C, Frasunek J, Myklebust I, Vonen B: Anal incontinence after obstetric sphincter tears: incidence in a Norwegian county. Acta Obstet Gynecol Scand 2004, 83:989-994.

5. Scheer I, Andrews V, Thakar R, Sultan AH: Urinary incontinence after obstetric anal sphincter injuries (OASIS)-is there a relationship? In Urogynecol J Pelvic Floor Dysfunct 2008, 19:179-183.

6. Abdool Z, Thakar R, Sultan AH: Postpartum female sexual function. Eur J Obstet Gynecol Reprod Biol 2009, 145:133-137.

7. Borello-France D, Burgio KL, Richter HE, Zyczynski H, Fitzgerald MP, Whitehead W, Fine P, Nygaard I, Handa VL, Visco AG, Weber AM, Brown MB: Fecal and urinary incontinence in primiparous women. Obstet Gynecol 2006, 108:863-872

8. Roos AM, Sultan AH, Thakar R: Sexual problems in the gynecology clinic: are we making a mountain out of a molehill? Int Urogynecol J 2012, 23:145-152.

9. Tincello DG, Williams A, Fowler GE, Adams EJ, Richmond DH, Alfirevic Z: Differences in episiotomy technique between midwives and doctors. BJOG 2003, 110:1041-1044.

10. Wong KW, Ravindran K, Thomas JM, Andrews V: Mediolateral episiotomy: are trained midwives and doctors approaching it from a different angle? Eur J Obstet Gynecol Reprod Biol 2014, 174:46-50.

11. Andrews V, Sultan AH, Thakar R, Jones PW: Risk factors for obstetric anal sphincter injury: a prospective study. Birth 2006, 33:117-122

12. Eogan M, Daly L, O'Connell PR, O'Herlihy C: Does the angle of episiotomy affect the incidence of anal sphincter injury? BJOG 2006, 113:190-194.

13. Handa VL, Blomquist JL, McDermott KC, Friedman S, Munoz A: Pelvic floor disorders after vaginal birth: effect of episiotomy, perineal laceration and operative birth. Obstet Gynecol 2004, 103:669-673.

14. Kalis V, Laine K, de Leeuw JW, Ismail K, Tincello D: Classification of episiotomy: towards a standardisation of terminology. BJOG 2012, 119:724-730.

15. Raisanen SH, Vehvilainen-Julkunen K, Gissler M, Heinonen S: Lateral episiotomy protects primiparous but not multiparous women from obstetric anal sphincter rupture. Acta Obstet Gynecol Scand 2009, 88:1365-1372.

16. Fodstad K, Laine K, Staff AC: Different episiotomy techniques, postpartum perineal pain, and blood loss: an observational study. Int Urogynecol J 2013, 24:865-872.

17. Grigoriadis T, Athanasiou S, Zisou A, Antsaklis A: Episiotomy and perineal repair practices among obstetricians in Greece. Int I Gynaecol Obstet 2009, 106:27-29.

18. Stedenfeldt M, Pirhonen J, Blix E, Wilsgaard T, Vonen B, Oian P: Episiotomy characteristics and risks for obstetric anal sphincter injuries: a case-control study. BJOG 2012, 119:724-730.

19. Andrews $V$, Thakar $R$, Sultan $A H$, Jones PW: Are mediolateral episiotomies actually mediolateral? BJOG 2005, 112:1156-1158.

20. Sartore A, De Seta F, Maso G, Pregazzi R, Grimaldi E, Guaschino S: The effects of mediolateral episiotomy on pelvic floor function after vaginal delivery. Obstet Gynecol 2004, 103:669-673.

21. Ejegard H, Ryding EL, Sjogren B: Sexuality after delivery with episiotomy: a long-term follow-up. Gynecol Obstet Invest 2008, 66:1-7.

22. Coats PM, Chan KK, Wilkins M, Beard RJ: A comparison between midline and mediolateral episiotomies. Br J Obstet Gynaecol 1980, 87:408-412.

23. Sultan AH: Obstetric perinealinjury and anal incontinence. Clinical Risk 1999, 5:193-196.

24. Vaizey CJ, Carapeti E, Cahill JA, Kamm MA: Prospective comparison of faecal incontinence grading systems. Gut 1999, 44:77-80.

25. Avery K, Donovan J, Peters TJ, Shaw C, Gotoh M, Abrams P: ICIQ: A brief and robust measure for evaluating the symptoms and impact of urinary incontinence. Neurourol Urodyn 2004, 23:322-330.
26. Klovning A, Avery K, Sandvik H, Hunskaar S: Comparison of two questionnaires for assessing the severity of urinary incontinence: The ICIQ-UI SF versus the incontinence severity index. Neurourol Urodyn 2009, 28:411-415

27. Traeen B, Stigum H: Sexual problems in 18-67-year-old Norwegians. Scand J Public Health 2010, 38:445-456.

28. Sultan AH, Thakar R: Third and Forth Degree Tears. In Perineal and Anal Sphincter Trauma. Edited by Sultan AH, Thakar R, Fenner D. London: Spinger-Verlag; 2007:33-51

29. Mous M, Muller SA, de Leeuw JW: Long-term effects of anal sphincter rupture during vaginal delivery: faecal incontinence and sexual complaints. BJOG 2008, 115:234-238.

30. Signorello LB, Harlow BL, Chekos AK, Repke JT: Postpartum sexual functioning and its relationship to perineal trauma: a retrospective cohort study of primiparous women. Am J Obstet Gynecol 2001, 184:881-888.

31. Kalis V, Landsmanova J, Bednarova B, Karbanova J, Laine K, Rokyta Z: Evaluation of the incision angle of mediolateral episiotomy at 60 degrees. Int J Gynaecol Obstet 2011, 112:220-224.

32. Bols EMJ, Hendriks EJM, Berghmans BCM, Baeten CGMI, Nijhuis JG, de Bie RA: A systematic review of etiological factors for postpartum fecal incontinence. Acta Obstet Gynecol Scand 2010, 89:302-314.

33. Solans-Domenech M, Sanchez E, Espuna-Pons M: Urinary and anal incontinence during pregnancy and postpartum: incidence, severity, and risk factors. Obstet Gynecol 2010, 115:618-628.

34. de Leeuw JW, Struijk PC, Vierhout ME, Wallenburg HC: Risk factors for third degree perineal ruptures during delivery. BJOG 2001, 108:383-387.

35. MacArthur C, Glazener C, Lancashire R, Herbison P, Wilson D, Grant A: Faecal incontinence and mode of first and subsequent delivery: a six-year longitudinal study. BJOG 2005, 112:1075-1082

doi:10.1186/s12905-014-0157-y

Cite this article as: Stedenfeldt et al:: Anal incontinence, urinary incontinence and sexual problems in primiparous women - a comparison between women with episiotomy only and women with episiotomy and obstetric anal sphincter injury. BMC Women's Health 2014 14:157.

\section{Submit your next manuscript to BioMed Central and take full advantage of:}

- Convenient online submission

- Thorough peer review

- No space constraints or color figure charges

- Immediate publication on acceptance

- Inclusion in PubMed, CAS, Scopus and Google Scholar

- Research which is freely available for redistribution 